\title{
GLI INTERVENTI DI RIFACIMENTO NELLA CATTEDRALE DI CURZOLA NEL XVIII SECOLO
}

\section{Dubravka Botica, Damir Tulić}

\author{
D. Botica \\ Department of History of Art \\ Faculty of Humanities and Social Sciences, University of Zagreb \\ Ivana Lučića 3 \\ HR-10000 Zagreb \\ dbotica@ffzg.hr \\ D. Tulić \\ Department of History of Art \\ Faculty of Humanities and Social Sciences, University of Rijeka \\ Sveučilišna avenija 4 \\ HR-51000 Rijeka \\ dtulic@ffri.hr
}

The Refurbishment of the Interior of the Korčula Cathedral in the $18^{\text {th }}$ Century

In the $17^{\text {th }}$ and $18^{\text {th }}$ centuries, all Korčula's churches were renewed and refurbished, including the Cathedral of St. Mark, built in the $15^{\text {th }}$ century. In $18^{\text {th }}$ century, new lighting was introduced and new main altar, with a marble antependium of the Venetian sculptor Bortolo Modolo. Particularly significant were the interventions during the last Bishop of Korčula Josip Kosirić (1787- 1802), aiming to establish complete symmetry within the space, for gaining more light into the dark interior, and for the introduction of modern liturgical furniture, especially in the unrealized projects of reconstruction of the presbitery and a new marble altar, modelled under the influence of Venetian settecento altars by Giorgio Massari. These procedures are analysed in comparison with similar interventions in cathedrals in Novigrad, Poreč, Osor, Rab and Zadar.

Key words: the cathedral of Korčula, bishop Josip Kosiric, baroque rennovation, Bortolo Modolo, presbytery plan, $18^{\text {th }}$ century

La cattedrale di San Marco a Curzola rappresenta uno dei più importanti monumenti sacri del XV secolo sulla costa orientale dell'Adriatico (fig. 1). ${ }^{1} \mathrm{Si}$ tratta di un edificio basilicale a tre navate e tre absidi (fig. 2). Le navate laterali sono diverse per quanto riguarda sia la larghezza che l'altezza, in quanto nel corso del XVI secolo lungo quella settentrionale è stata aggiunta la cappella di San Rocco. Sopra di esse, inoltre, si trovano due gallerie collegate alla centrale da una serie di bifore. Nella porzione superiore delle pareti della navata centrale, che presenta una copertura lignea a carena di nave,

\footnotetext{
${ }^{1}$ Sulla costruzione della cattedrale si vedano C. FISKOVIĆ, Korčulanska katedrala, Zagreb 1939; I. FISKOVIĆ, Kulturno umjetnička prošlost pelješkog kanala, Split 1983, pp. 41-46, 64-65; G. NIKŠIĆ, Povijest i arhitektura korčulanske katedrale svetog Marka; in 700 godina korčulanske biskupije, I. FISKOVIĆ, M. STANIĆ (a cura di), Korčula 2005, pp. 118-134; D. TULIĆ, N. KUDIS, Opatska riznica, katedrala i crkve grada Korčule, Korčula 2014, pp. 151-210.
} 


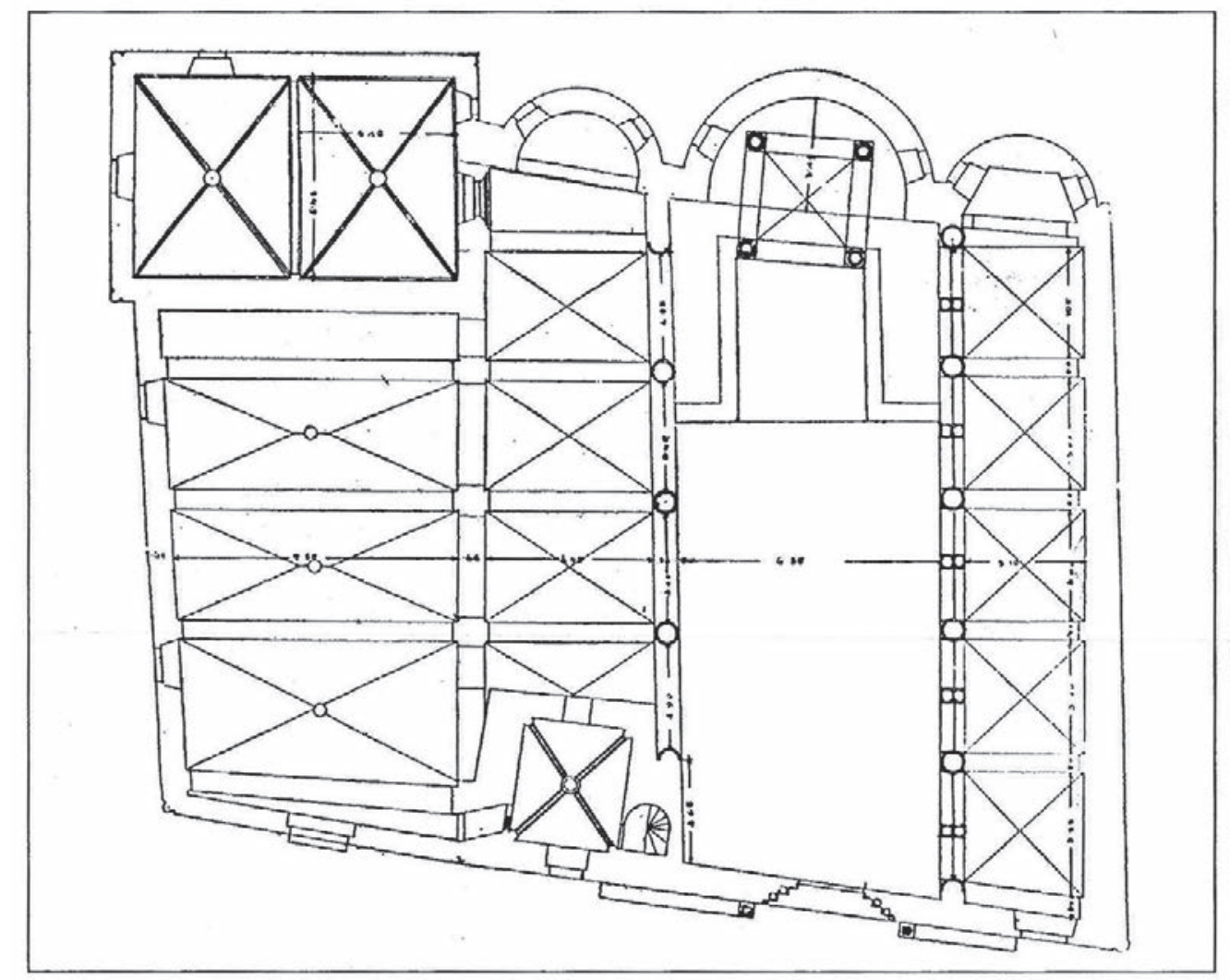

Fig. 1. Planimetria della cattedrale di Curzola di Ćiril Metod Iveković del 1927.

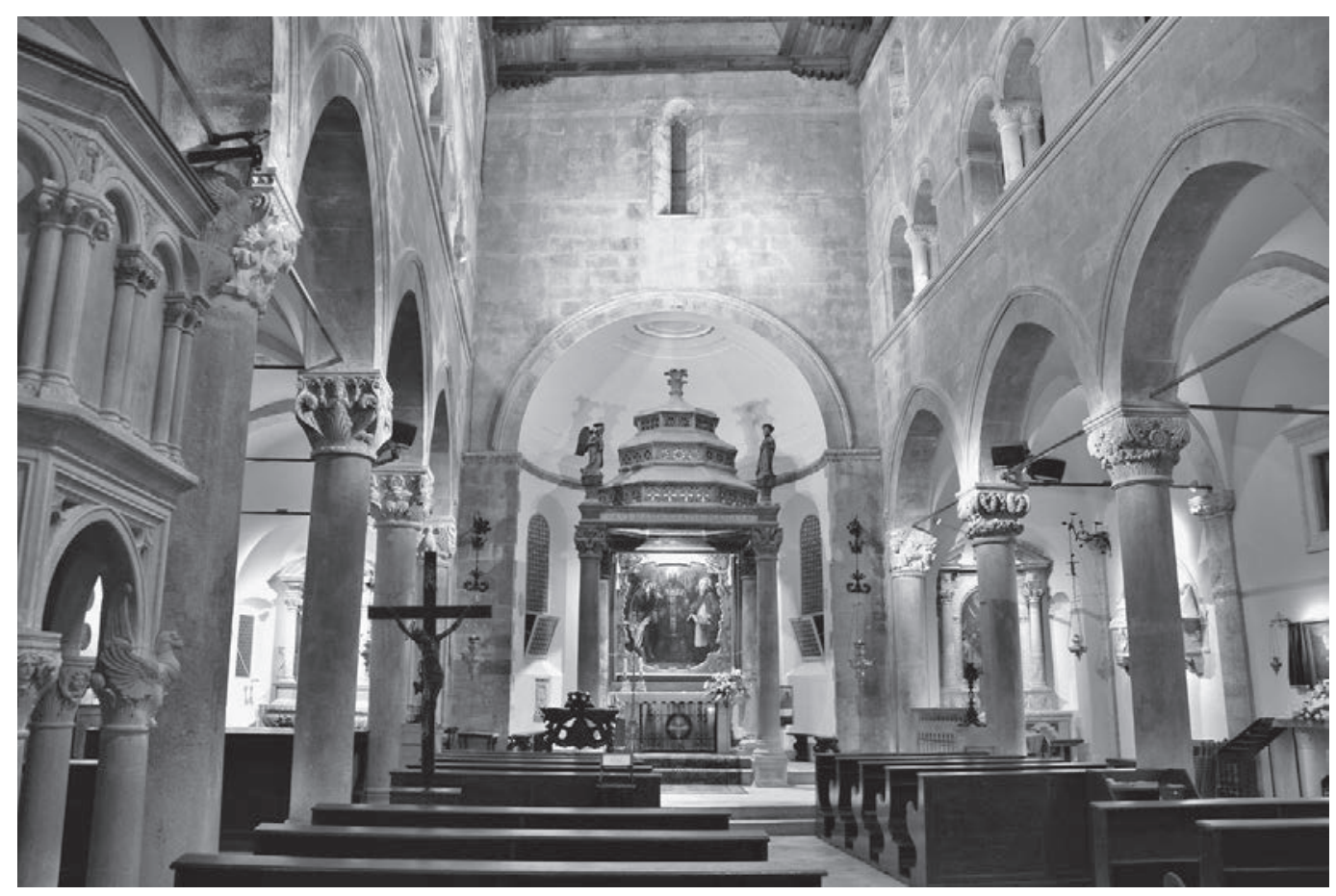

Fig. 2. Interno della cattedrale, Curzola, stato attuale. 
si aprono strette finestre gotiche. In quelle laterali il soffitto è invece a volte a crociera. Gli elementi architettonici cupi e massicci, la scarsa illuminazione delle arcate e delle pareti a prima vista conferiscono all'edificio un aspetto molto più antico di quanto non sia effettivamente. Sebbene realizzata nel XV secolo, lo spazio interno della cattedrale presenta forti caratteri romanici, quasi fosse una costruzione pienamente medievale.

Nel XVII secolo, e più precisamente nel 1626, su ordine del vescovo Giacomo Fagagna furono aperte in tutte tre le absidi finestre laterali per consentire una maggiore illuminazione del presbiterio. ${ }^{2}$ Nella seconda metà del Seicento vennero rifatti tre dei sette capitelli delle massicce colonne che dividono la navata centrale da quelle laterali; questi, infatti, erano stati danneggiati da alcuni fulmini che avevano colpito la chiesa. ${ }^{3}$ Oltre al ripristino della decorazione architettonica, l'interno della cattedrale venne arricchito da due nuovi altari: nel 1620 fu costruito l'altare lapideo della Santissima Trinità e nel 1672 la famiglia Španić fece erigere l'altare mar-

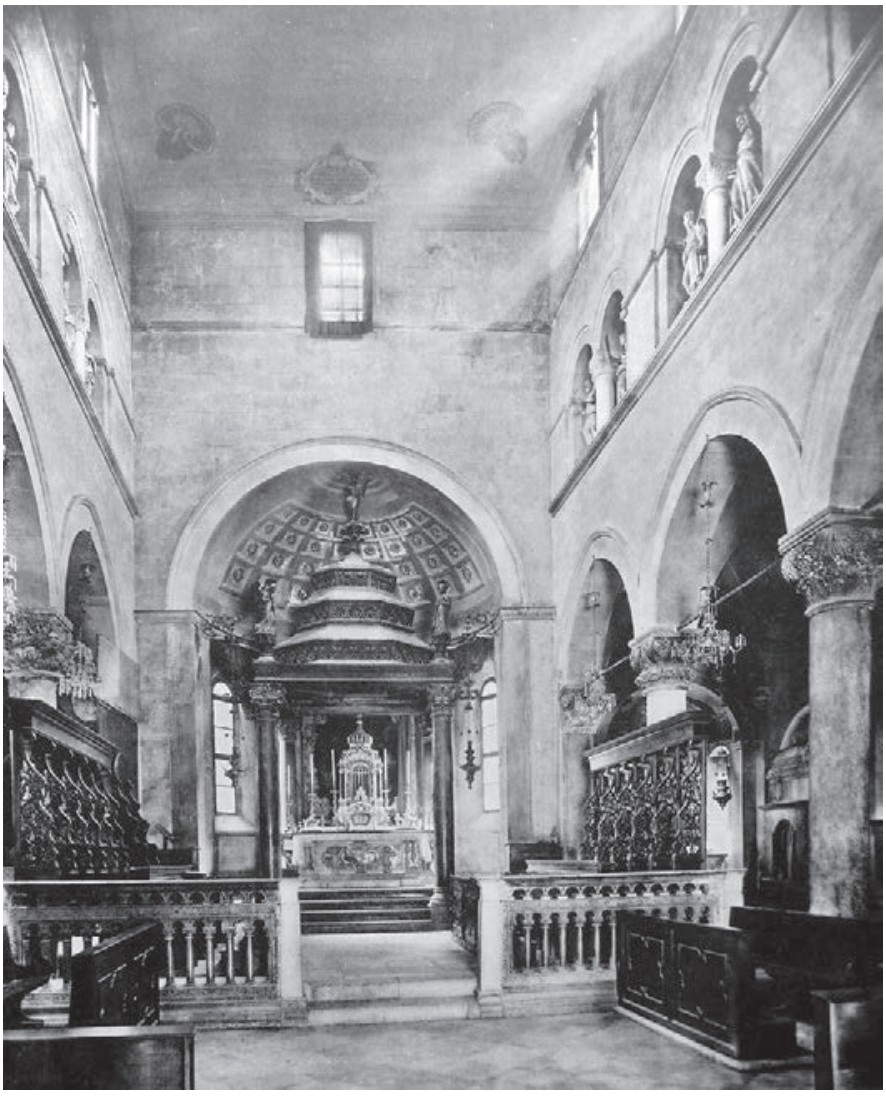

Fig. 3. Interno della cattedrale, Curzola, fotografia del 1910. moreo dedicato a Sant'Antonio da Padova. ${ }^{5}$

Nel Settecento gli interventi sono stati più vasti e articolati, in primo luogo per quanto attiene il presbiterio e l'altare maggiore (fig. 3). Questo spazio era stato in gran parte definito architettonicamente già nel 1468, quando Marko Andrijić vi costruì il grande ciborio lapideo a quattro colonne che reggono una copertura ottagonale, che in origine era composta da quattro piani a forma di tenda. ${ }^{6}$ Verso la metà del Cinquecento venne collocato sull'altare il grande dipinto di Jacopo Tintoretto con la raffigurazione di San Marco e i santi Bartolomeo e Girolamo: Marco assieme a Bartolomeo e Girolamo è, infatti, titolare della cattedrale e patrono sia della città che dell'intera diocesi. ${ }^{7}$ Contestualmente lo

${ }^{2}$ C. FISKOVIĆ, op. cit., p. 26 (n. 1).

${ }^{3}$ Ibidem, pp. 45-46.

${ }^{4}$ C. FISKOVIĆ, Hvarska katedrala, Split, 1976, p. 32.

${ }^{5}$ D. TULIĆ, N. KUDIŠ, Opatska riznica ..., pp. 171-175 (n. 1).

${ }^{6}$ C. FISKOVIĆ, Korčulanska katedrala ..., pp. 55-56, $89-90$ (n. 1); G. NIKŠIĆ, Marko Andrijić u Korčuli i Hvaru, in Prilozi povijesti umjetnosti u Dalmaciji, 37, Split, 1997-1998, pp. 216-220; J. BELAMARIĆ, Ciborij Marka Andrijića - prijedlog izvornog oblika, in Studije iz srednjovjekovne i renesansne umjetnosti na Jadranu, J. BELAMARIĆ (a cura di), Split, 2001, pp. 366-368.

${ }^{7}$ D. WESTPHAL, Malo poznata slikarska djela XIV-XVIII stoljeća u Dalmaciji, in Rad Jugoslavenske akademije znanosti i umjetnosti, 258, Zagreb, 1937 p. 40; C. FISKOVIĆ, Korčulanska katedrala ... , pp. 58,95 (n. 1); G. GAMULIN, Due dipinti ignoti e poco sconosciuti, in Arte Veneta, X, Venezia, 1956, pp. 65-71, K. ALAMAT KUSIJANOVIĆ, Oltarna pala Jacopa Tintoretta iz korčulanske katedrale, in Renesansa i renesanse u umjetnosti Hrvatske, Zbornik radova sa znanstvenih skupova "Dani Cvita Fiskovića" održanih 2003. i 2004. godine, J. GUDELJ, P. MARKOVIĆ (a cura di), Zagreb, 2008, pp. 255-268; R. TOMIĆ, Jacopo Tintoretto i radionica: Sv. Marko, sv. Jeronim i sv. Bartolomej, in Tizian, Tintoretto, Veronese, veliki majstori renesanse, Katalog izložbe, Galerija Klovićevi dvori, Zagreb, 22. studenog 2010 - 22 siječnja 2011, R. TOMIĆ (a cura di), Zagreb, 2011, pp. 210-213; D. TULIĆ, N. KUDIS, Opatska riznica ..., pp. 190-193 (n.1). 
spazio davanti l'altare maggiore fu delimitato lateralmente con gli stalli corali per i canonici, opera risalente al 1552 dell'intagliatore Venturino di Donato. ${ }^{8}$ Sopra l'ingresso del coro su una trave lignea si trovava un grande crocefisso ligneo al di sotto il quale pendeva una lampada in argento. ${ }^{9}$ All'inizio del Seicento venne trasportato sull'altare maggiore il Santissimo Sacramento, che in precedenza era custodito in una nicchia sulla parete sinistra del presbiterio. Da allora è conservato in un tabernacolo ligneo dorato che il vescovo Marino Drago così descriveva nel testo della visita pastorale del 1719: «in piu luoghi rotto, et manchante di tante colonette, vase et statuette». ${ }^{10}$ L'altare maggiore così strutturato non era adatto ad accogliere l'arca con le reliquie del corpo di san Teodoro protomartire (in dialetto locale Todor) che nel 1736 il vescovo di Curzola Vicko Kosović (1734-1761) aveva ricevuto da papa Clemente XII. ${ }^{11}$ Si dovette quindi provvedere al rifacimento dell'altare maggiore per poter alloggiare l'arca e nel $1750 \mathrm{fu}$ commissionato a Venezia un paliotto in marmo. Esso venne realizzato dallo scultore Bortolo Modolo e dal suo abituale collaboratore, il lapicida e altarista Iseppo Caribolo. ${ }^{12} \mathrm{Si}$ tratta di uno scultore sconosciuto agli studiosi che si sono occupati della cattedrale e delle sue opere, ma in realtà era un artista molto operoso, nato a Venezia nel 1684 e attivo fino alla morte nel 1771. ${ }^{13}$ Le opere risalenti alla fase tarda della sua produzione si presentano nell'insieme qualitativamente più scadenti: la resa delle superfici è più sommaria, le proporzioni più grossolane, come si evince nei due piccoli putti che reggono la cornice ovale con le portelle di ottone che cela l'arca con le reliquie del santo. Nelle opere di Modolo si rilevano gli influssi della scultura veneziana coeva, per esempio di artisti come Antonio Tarsia (1662-1739), Giovanni Bonazza (1654-1736) e di suo figlio Francesco (1695-1770). ${ }^{14}$ Questo paliotto eseguito a rilievo rappresenta la prima composizione figurativa eseguita su marmo presente nella città di Curzola. I committenti locali erano abituati a richiedere manufatti in pietra estratta dalle cave dell'isola e pertanto non è affatto strano che le prime sculture in marmo risalgano appena alla metà del Settecento.

La più vasta opera di rifacimento della cattedrale di Curzola si deve, però, all'azione del suo ultimo vescovo, Josip Kosirić (1787-1802) (fig. 3). Abbastanza è stato scritto finora su questi interventi, ma sostanzialmente valutandoli in modo negativo e senza un'analisi più approfondita degli stessi. ${ }^{15}$ Il suo radicale lavoro di rifacimento, ossia la rimozione del vecchio arredo liturgico e la sua sostituzione con nuovi manufatti, era coerente con i coevi interventi di restauro tardobarocco, come per esempio quelli delle cattedrali di Cittanova, Parenzo, Ossero, Arbe o Zara. I suoi interventi testimoniano il forte desiderio di conferire allo spazio dell'edificio la più compiuta simmetria in modo tale da ottenere

\footnotetext{
${ }^{8}$ C. FISKOVIĆ, Zadarski srednjovječni majstori, Split, 1959, p. 88.

${ }^{9}$ I. MATIJACA, Katedrala iznutra - nekada, in Lanterna svetog Marka, 5-6, Korčula, 1973, pp. 39-41; A. FAZINIĆ, I. MATIJACA, Srebrni svijećnjaci i svjetiljke korčulanskih crkava, in Peristil, 24, Zagreb, 1981, p. 125.

${ }^{10}$ D. TULIĆ, Drvena skulptura u Korčuli od 16. do 20. stoljeća, tesi di laurea, Università degli Studi di Zara, Zadar, 2005, p. 10

${ }^{11}$ D. TULIĆ, Povijest svetog Todora i njegovi likovni prikazi u gradu Korčuli, in Godišnjak grada Korčule, 7, Korčula, 2002, pp. 134-141.

${ }^{12}$ C. FISKOVIĆ, Likovni i urbanistički spomenici općine Korčula i njihova zaštita, [1971], in Korčulanske studije i eseji, V. FISKOVIĆ, D. TULIĆ (a cura di), Korčula, 2008, pp. 127.

${ }^{13}$ T. SHARMAN, Bortolo Modolo, in La scultura a Venezia dal Sansovino a Canova, A. BACCHI (a cura di), Milano, 2000, p. 763; P. GOI, Presenze di altaristi e scultori del Settecento in Friuli: Modolo, Caribolo, Trognon, in Atti dell'Accademia "San Marco" di Pordeneone, 16, Pordenone, 2014, p. 592-597.

${ }^{14}$ D. TULIĆ, N. KUDIŠ, Opatska riznica ..., p. 187 (n. 1).

${ }^{15}$ P. DIMITRI, Descrizione di tutte le chiese di Curzola ed altari che esistono nella citta e Borghi di Curzola, sine data (manoscritto, prima metà del XIX secolo) dattiloscritto di don Božo Baničević, 1996, pp. 10-17; T. G. JACKSON, Dalmatia the Quarnero and Istria, II, Oxford, 1887, p. 253, 263; C. FISKOVIĆ, Korčulanska katedrala..., p. 27, 50-51, 66-67, 98-100 (n. 1); A. FAZINIĆ, Restauratorski radovi na korčulanskoj katedrali, in Croatica Christiana Periodica, 9, Zagreb, 1980, p. 27-28; B. BANIČEVIĆ, Korčulanska biskupija (1300. - 1800.), Split, 2003, p. 282-286; V. B. LUPIS, Josip Kosirić Teodošević biskup Korčulanski (1787. - 1802.), in Godišnjak grada Korčule, 10, Korčula, 2005, p. 186-187.
} 
una maggiore illuminazione dell'ambiente interno e potervi collocare i nuovi arredi. In quest'ottica fece demolire il grande pulpito marmoreo a otto colonne del 1445 che si trovava accanto alla seconda colonna della navata settentrionale, come pure l'altare di San Giacomo collocato sotto di esso. ${ }^{16}$ Il pulpito medievale interferiva con la sua aspirazione ai principi della simmetria, che costituivano i cardini della riorganizzazione degli interni verso la fine del Settecento. Ciò viene corroborato dal fatto che il presule, dopo la rimozione del grande pulpito ne fece costruire altri due lignei di minori dimensioni che vennero collocati in modo, appunto, simmetrico uno di fronte all'altro. Furono rimossi l'altare dell'Ascensione con il piccolo ciborio quattrocentesco che si trovava a sinistra appoggiato all'arco trionfale, e i vecchi stalli corali rinascimentali. In questo modo venne completamente liberato lo spazio del presbiterio. Kosirić commissionò un nuovo coro molto più grande composto da due sezioni ognuna con dieci seggi. L'opera venne progettata e realizzata nel 1795 dall'intagliatore Vincenzo Tironi di Brazza. ${ }^{17}$ Accanto ai sedili, al posto dell'altare del'Ascensione venne collocata una grande cattedra episcopale con tendaletto d'onore e baldacchino. Otto canonici della cattedrale si opposero con il sostegno della cittadinanza alla rimozione dell'antico coro; è probabile che oltre a prodigarsi per la conservazione dell'antico patrimonio artistico, i canonici abbiano avversato anche l'aggiunta di nuovi scranni per i semplici sacerdoti.

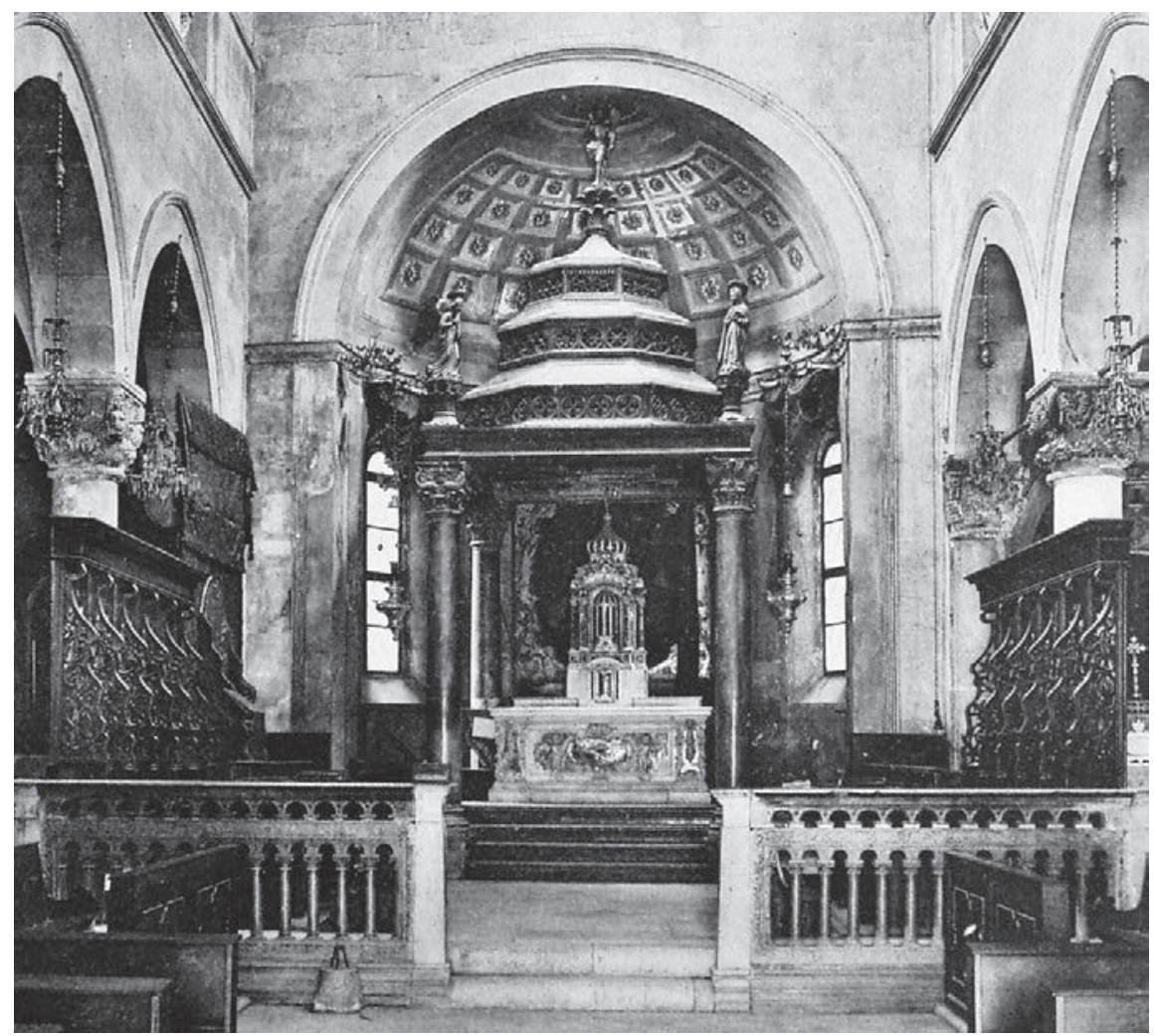

Fig. 4. Presbiterio della cattedrale, Curzola, fotografia del 1910.

Gli interventi di Kosirić nel presbiterio interessarono anche l'altare maggiore: è probabile che lo ritenesse nel suo insieme, ossia il ciborio lapideo e la pala d'altare con cornice lignea, antiquato rispetto alle mode del tempo (fig. 4). Il vescovo quindi fece togliere l'ultimo piano della copertura del ciborio e al suo posto venne messa una scultura lignea raffigurante il Cristo risorto. Questo intervento corrisponde alla quasi contemporanea collocazione di una scultura lignea di medesimo soggetto sul

\footnotetext{
${ }^{16}$ C. FISKOVIĆ, Korčulanska katedrala..., p. $67-68$ (n. 1).

${ }^{17}$ Ibidem, p. 66.
} 
ciborio gotico della cattedrale di Zara. ${ }^{18}$ Kosirić fece rimuovere dagli intercolunni laterali del ciborio le balaustre composte da colonnette risalenti al 1486, che vennero collocate nella navata centrale come recinto del presbiterio. Per l'altare maggiore ordinò a Venezia nel 1791 presso l'altarista Domenico Daparo un tabernacolo marmoreo con il trono per l'ostensorio. ${ }^{19}$ I canonici della cattedrale, però, ritennero questo nuovo tabernacolo troppo piccolo e pertanto venne venduto alla chiesa parrocchiale di Smokvica, sempre sull'isola di Curzola. Nel 1796, quindi, ne venne commissionato uno nuovo e più grande, opera senza dubbio anche questa di Daparo. ${ }^{20}$ Infine il presule si decise a mettere mano a un altro elemento che riteneva obsoleto: la trave lignea che si trovava in alto al di sopra dell'ingresso al coro e il grande Crocefisso collocato in cima ad essa.

Contemporaneamente ordinò che l'intera cattedrale e tutti i suoi elementi architettonici venissero ridipinti di colore bianco. Questo tipo di intervento non era affatto insolito in quel periodo. Similmente, per esempio, il vescovo di Traù Giuseppe Caccia (1731-1738) fece dipingere di bianco tutte le pareti lapidee della sua cattedrale. ${ }^{21}$ Kosirić, inoltre, decise di aumentare l'apertura delle strette finestre gotiche poste nella parte superiore delle pareti laterali della navata centrale per ottenere una maggiore illuminazione, al fine di creare un theatrum sacrum di potente effetto. In tale contesto va inserito anche l'acquisto a Venezia nel 1800 di dodici statue lignee raffiguranti gli apostoli. ${ }^{22}$ Le fece dipingere con colori vivaci e le fece collocare nelle bifore delle due gallerie laterali, che vennero murate e pertanto trasformate in nicchie. L'ultimo grande intervento del vescovo nella cattedrale riguarda il soffitto a carena di nave che venne chiuso con una copertura piana a stucco ma priva di particolari decorazioni. ${ }^{23}$ Questo nuovo soffitto che copriva quello precedente trova un parallelo in coperture analoghe che vennero realizzate in quel periodo nelle cattedrali di Arbe e Zara per celare i più antichi soffitti lignei. ${ }^{24}$ Lo scopo di questi nuovi rivestimenti era quello di ottenere una maggiore illuminazione, di modernizzare e abbellire gli antichi spazi interni delle chiese.

Con quest'ultimo intervento tutta la cattedrale costruita con pietra di Curzola assunse un aspetto chiaro, divenne un edificio pieno di luce simile alle chiese settecentesche rivestite di intonaco bianco, come se ne possono trovare in Terraferma veneziana. Infine, il vescovo Kosirić intervenne anche sulla controfacciata, provvedendo a una nuova bussola lignea con la cantorìa e un grande armadio dorato per l'organo. Dopo la costruzione della cappella di San Rocco nel XVI secolo, quello realizzato nel corso dell'ultimo decennio del Settecento rappresenta il più consistente intervento di rifacimento effettuato nella cattedrale.

${ }^{18}$ I. PETRICIOLI, Katedrala sv. Stošije - Zadar, Zadar, 1985, p. 20; R. TOMIĆ, Kiparstvo II od XVI. Do XX. stoljeća (Umjetnička baština zadarske nadbiskupije), Zadar, 2008, p. 192-194. La scultura lignea del Cristo risorto per il ciborio della cattedrale di Zara, che attualmente presenta gravissime lesioni, è opera risalente al 1782 dell'intagliatore veneziano Francesco Zotti.

${ }^{19}$ P. DIMITRI, Descrizione... op. cit. p. 13-14 (n. 15); V. B. LUPIS, Josip Kosirić .... pp. 196-197 (n. 15).

${ }^{20}$ D. TULIĆ, N. KUDIŠ, Opatska riznica..., p. 248-249 (n.1).

${ }^{21}$ I. BABIĆ, Giuseppe Torretti nella cattedrale di Traù, in Francesco Robba an the Venetian Sculpture of the Eighteenth Century, Papers from an International Symposium, Ljubljana $16^{\text {th }}-18^{\text {th }}$ October 1998, J. HÖFLER (a cura di), Ljubljana, 2000, p. 217.

${ }^{22}$ C. FISKOVIĆ, Uz četiri nacrta Josipa Zmajića [1983], in Korčulanske studije i eseji, V. FISKOVIĆ, D. TULIĆ (a cura di), Korčula, 2008, pp. 223-224.

${ }^{23}$ Il soffitto a stucco era costituito da un cornicione dal profilo lineare, mentre nei quattro angoli erano collocate semplici conchiglie a rilievo e un cartouche con iscrizione al di sopra della finestra centrale del presbiterio. Dalle immagini fotografiche si rileva che si trattava di un'opera di scarso valore e che gli ornamenti a stucco erano di fattura rigida e del tutto semplificati. Sulla base della datazione alla fine del XVIII secolo, si può concludere che siano stati realizzati dal lapicida e artigiano locale Mato Jeričevć Labut. Questi proprio nel 1800 costruì la cupola lignea ellissoidale nel presbiterio della chiesa di San Michele sempre a Curzola, i cui semplici profili a stucco e gli elementi decorativi a forma di nastro e raffiguranti la Colomba dello Spirito Santo ricordano quelli che un tempo si trovavano nella cattedrale.

${ }^{24}$ I. PETRICIOLI, Katedrala..., p. 20-21 (n.18). 
Va comunque rilevato, che probabilmente tutti gli interventi elencati sono solo la conseguenza dell'impossibilità di attuazione pratica di un progetto che va analizzato in modo più dettagliato $\mathrm{e}$ preciso. Si tratta di un intervento pianificato ma mai realizzato, documentato dalla planimetria del presbiterio della cattedrale che è stata usata in un periodo successivo come copertina degli atti notarili di Girolamo Arneri del 1838, conservati presso l'Archivio di Stato di Ragusa (fig. 5). La planimetria è stata pubblicata da Vinicije B. Lupis, il quale credeva si trattasse della situazione del ciborio e dell'abside dopo l'intervento di epoca barocca, molto probabilmente della metà del XVIII secolo, ossia di quando era vescovo Vicko Kosović. ${ }^{25}$ Allora, infatti, venne collocato sull'altare maggiore il sarcofago con le reliquie di san Teodoro. Diversa è l'opinione di Goran Nikšić, il quale ritiene che le colonne disegnate nella planimetria non siano quelle del ciborio bensì della navata centrale e che pertanto era prevista la rimozione totale del ciborio stesso. ${ }^{26}$

Una più precisa interpretazione di questa planimetria è possibile solo se si comprende il contesto degli interventi eseguiti dal vescovo Josip Kosirić alla fine del Settecento. La planimetria rappresenta il presbiterio, ossia lo spazio tra l'ultimo intercolunnio delle navate settentrionale e meridionale e l'abside centrale della cattedrale. Con la lettera

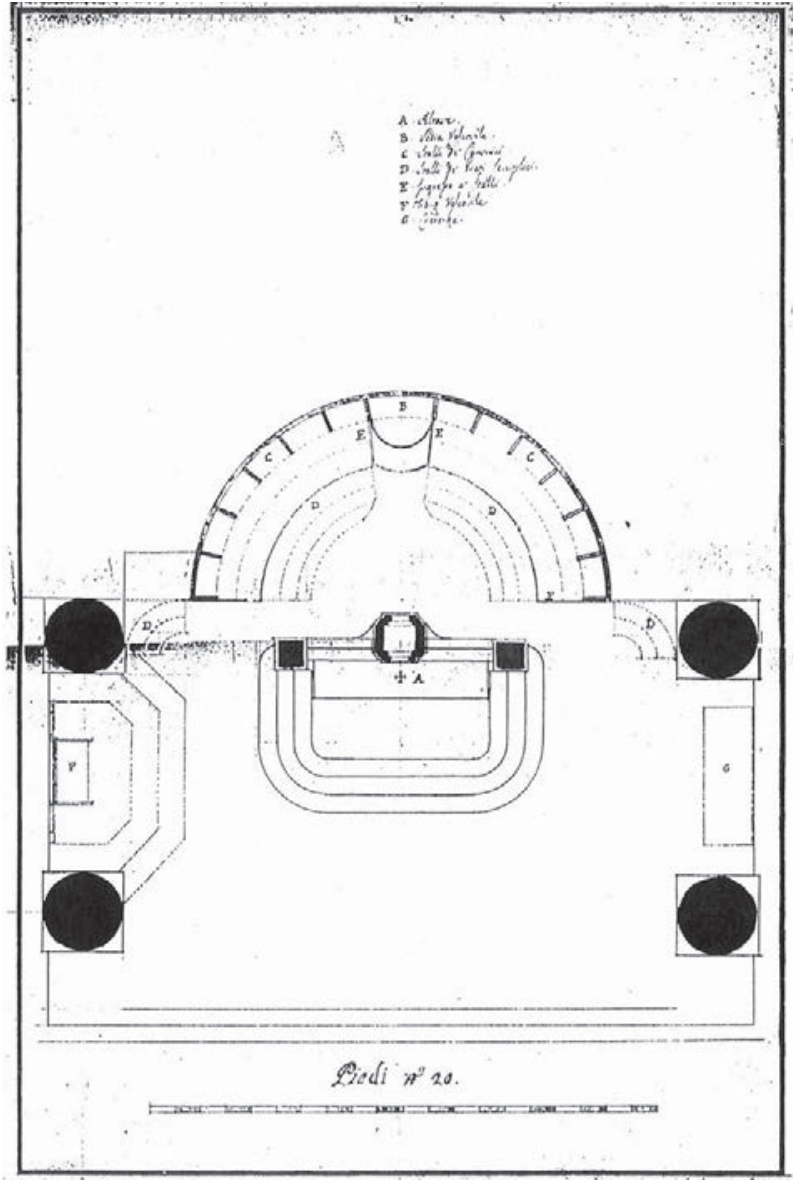

Fig. 5. Planimetria del progetto, non realizzato, di rifacimento del presbiterio della Cattedrale di Curzola, ultimo quarto del XVIII secolo. $A$ è contrassegnato il nuovo altare maggiore senza ciborio e posto davanti l'abside, quindi un poco più vicino ai fedeli di quello tutt'ora esistente. La novità consiste nel fatto che l'altare è isolato e rialzato su quattro gradini. Sopra la mensa si eleva il tabernacolo. È lecito ipotizzare che la forma della mensa doveva essere adatta ad accogliere il tabernacolo con il trono per l'ostensorio comprato a Venezia nel 1796. Ai lati del tabernacolo erano previsti due basamenti su cui porre due statue, molto verosimilmente angeli adoranti o i due santi protettori della città Marco Evangelista e Teodoro protomartire. Il nuovo altare con questa forma, secondo quanto si ricava dalla planimetria, corrisponde pienamente alla tipologia degli altari veneziani in voga nel XVIII secolo, il cui esempio più rappresentativo sono le opere del più importante architetto e altarista veneziano del Settecento Giorgio Massari (1687-1766). In particolare va posta l'attenzione sul suo altare maggiore che si trova nella chiesa di Santa Maria della Consolazione a Venezia eseguito a metà del secolo, oppure sull'altare maggiore della cattedrale di Pordenone o quello della parrocchiale di Crespano del Grappa. ${ }^{27}$ Anche se non si può evincere dalla planimetria, è lecito ipotizzare che il sarcofago con il corpo santo di san Teodoro sarebbe dovuto restare sotto la mensa

\footnotetext{
${ }^{25}$ V. B. LUPIS, Novi prilozi za korčulansku baštinu, in Godišnjak grada Korčule, 8, Korčula, 2003, p. 117-118.

${ }^{26}$ G. NIKŠIĆ, Marko Andrijić i njegov doprinos dalmatinskom renesansnom graditeljstvu, tesi di dottorato di ricerca, Università degli Studi di Zagabria, Zagreb 2012., p. 110-111.

${ }^{27}$ H. SERAŽIN, Arhitekt Giorgio Massari (1687 - 1766) Sakralna arhitektura na Goriškem, v Furlaniji, Istri in Dalmaciji, Ljubljana, 2007, p. 186-193.
} 
come era stato deciso in occasione della traslazione nel 1756. L'intervento prevedeva lo spostamento dell'altare verso il presbiterio e la rimozione del ciborio, pertanto tutta l'abside centrale era libera per accogliere la cattedra episcopale contrassegnata dalla lettera $B$. Alla sua destra e alla sua sinistra sono disegnati sei seggi semicircolari per lato destinati ai canonici, contrassegnati dalla lettera $C$, e a cui si accede attraverso l'entrata contrassegnata dalla lettera $E$ davanti la cattedra. Nell'ordine inferiore sotto i sedili per i canonici con schienale si trovano le panche semicircolari per i sacerdoti contrassegnate con la lettera $D$. Questo progetto di ampliamento e modernizzazione del coro in cui quotidianamente si pregava il breviario, corrisponde proprio al progetto del vescovo Kosirić che ha aumentato il numero degli stalli del coro includendo anche i sacerdoti, nonostante l'opposizione dei canonici della cattedrale. ${ }^{28}$ Inoltre, nella planimetria sul lato sinistro del presbiterio è rappresentato uno spazio nell'intercolunnio in cui trova posto un podio innalzato su tre gradini con un grande trono per il vescovo. Esso doveva essere utilizzato in occasione delle messe solenni ed è contrassegnato dalla lettera $F$. Di fronte, nell'intercolunnio destro era previsto un armadio, contrassegnato dalla lettera $G$, per custodire il necessario per la liturgia.

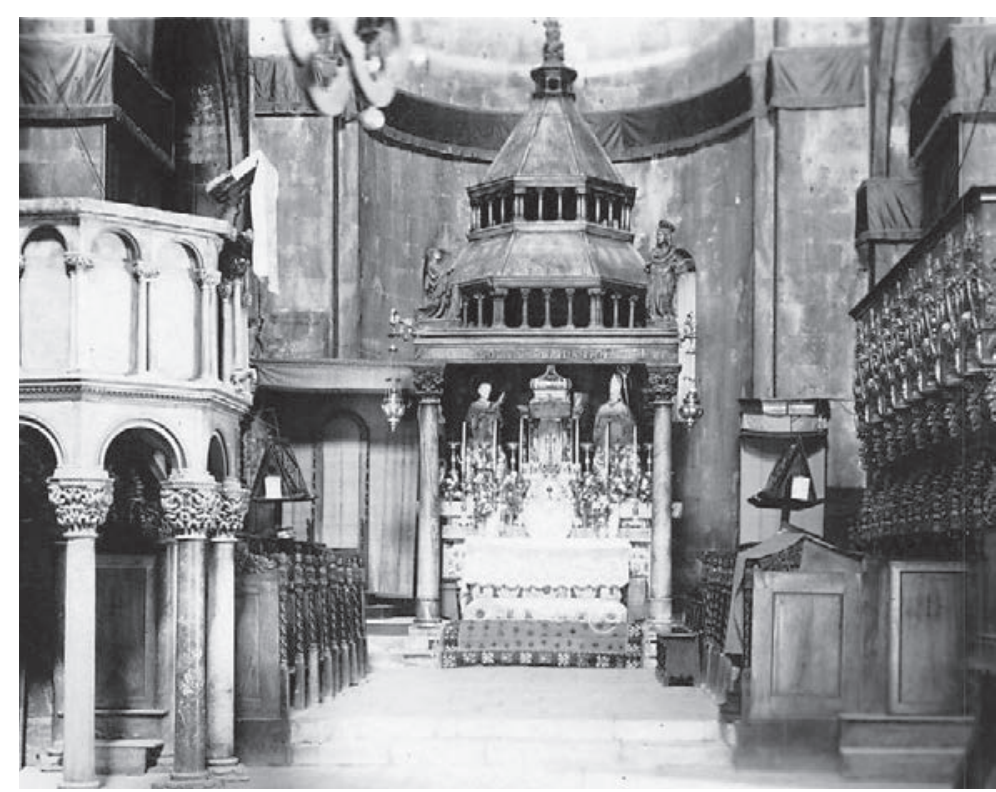

Fig. 6. Ciborio della cattedrale prima della rimozione dell'altare maggiore, Traù, fotografia del 1930.
Un simile rinnovamento dello spazio absidale non era né inconsueto né un caso isolato. Basti ricordare che le benedettine del monastero di Santa Maria a Zara fecero demolire il ciborio del re Koloman sopra l'altare maggiore. Al suo posto tra il 1759 e il 1762 l'altarista veneziano Lorenzo Bon costruì un altare con un grande tabernacolo e un trono ai cui lati si trovano due angeli di Giovanni Maria Morlaiter. ${ }^{29}$ L'altare zaratino presenta le stesse caratteristiche di quello disegnato nella planimetria di Curzola. L'altare maggiore della cattedrale di Traù di poco precedente ha la stessa forma, anche se comunque l'intervento è meno radicale. Infatti il vescovo Giuseppe Caccia ha inserito sotto il ciborio un altare in marmo con taber-

nacolo ai cui lati si trovano le sculture dei santi protettori della città, Lorenzo e Giovanni Orsini, opera di Giuseppe Torretti del 1738 (fig. 6). ${ }^{30}$

Per quanto riguarda le panche semicircolari o poligonali nell'abside dietro l'altare così come sono disegnate nella planimetria di Curzola, è possibile trovare tutta una serie di esempi simili risalenti al XVIII secolo nelle collegiate in Istria. Per esempio gli spazi con gli stalli corali di Buie, Montona, Rovigno, Pinguente sono realizzati in modo tale che l'altare occupi la posizione più importante mentre i seggi dietro di esso permettono una maggiore riservatezza del clero nella preghiera del breviario.

Infine si pone la domanda sul perché a Curzola, per fortuna, non sia stata realizzata questa modernizzazione dell'abside. Si può ipotizzare che un simile intervento, in particolare l'acquisto a Venezia di un nuovo altare in marmo corredato di statue, fosse semplicemente troppo oneroso eco-

\footnotetext{
${ }^{28}$ B. BANIČEVIĆ, Korčulanska biskupija ..., p. 283. (n. 15)

${ }^{29}$ R. TOMIĆ, Kiparstvo II... p. 176-180 (n. 18).

${ }^{30}$ I. BABIĆ, Giuseppe Torretti... p. 217, 221 (n. 21). Tutto il complesso altaristico con le statue e il tabernacolo è stato rimosso dopo il Concilio ecumenico del 1965.
} 
nomicamente per la povera diocesi dell'isola. Ma non bisogna nemmeno dimenticare l'opposizione dei canonici e persino le controversie giuridiche, il cui scopo era quello di impedire al vescovo radicali interventi di rifacimento dell'edificio. Tutti i lavori del presule sono stati fatti sostanzialmente "in economia", è stato usato il legno, i materiali sono poco costosi, le opere sono state realizzate da maestranze locali. Per esempio, gli stalli del coro sono stati eseguiti dal falegname Vicenzo Tironi di Brazza; la bussola, i confessionali e la cantorìa con l'armadio dell'organo sono opera di Rafael Glegh di Ragusa; il soffitto reso tecnicamente e visivamente in modo mediocre è ascrivibile forse al maestro locale Mato Juričević Labut.

Per quanto riguarda invece le opere d'arte comprate a Venezia si tratta di vecchie sculture lignee e non in marmo, di cui solo in seguito è stato appurato il vero valore artistico. ${ }^{31}$ Sembra quindi che la massima spesa effettuata per l'acquisizione di arredi marmorei sia stata quella di 720 fiorini per l'acquisto a Venezia del tabernacolo.

Gli interventi di ripristino della situazione antecedente l'azione del vescovo Kosirić sono iniziati già nella seconda metà del XIX secolo, quando nel 1873 è stata levata la ridipintura bianca dalle pareti lapidee. Nel 1925 sono state riaperte le bifore delle due gallerie e nel 1931 sono stati rimossi i due pulpiti lignei ed è stato collocato un grande pulpito in stile storico sul modello di quello quattrocentesco fatto demolire dal presule. ${ }^{32}$ Nell'ambito della complessiva opera di restauro dei monumenti sacri di Curzola promossa dell'abate mitrato Ivo Matijaca (1950-1986) gli interventi più ampi sono quelli realizzati nella cattedrale tra il 1950 e il 1970. È stato tolto il soffitto piano nella navata centrale, sono state ricostruite le finestre gotiche, rimossi la bussola e l'armadio dell'organo, sono stati spostati gli stalli del coro, è stato smontato l'altare barocco con il tabernacolo; le statue degli apostoli, che si trovavano nelle bifore, sono state trasferite nella vicina chiesa di San Pietro.

Analizzando i rifacimenti e i rimaneggiamenti dell'interno della cattedrale di Curzola nel corso del Sei e Settecento si può concludere che si è trattato in prevalenza di una sostituzione di arredi vecchi con nuovi, o di riparazioni di parti danneggiate di elementi architettonici e scultorei lapidei. Tuttavia, gli interventi che l'ultimo vescovo di Curzola Josip Kosirić aveva pianificato e in gran parte portato a termine, testimoniano il tentativo di modificare in modo più serio l'organizzazione della navata centrale e dell'abside. La rimozione degli arredi liturgici più antichi aveva lo scopo di ottenere una simmetria, mentre la ridipintura bianca e l'ampliamento delle finestre era finalizzato a una maggiore illuminazione - strumento principale per ottenere un ambiente liturgico il più suggestivo possibile. L'incompiuto piano di rimozione del ciborio e di costruzione di un tabernacolo isolato con un coro semicircolare retrostante, testimonia il tentativo di introdurre nello spazio dell'antica cattedrale cambiamenti moderni, tipici della seconda metà del XVIII secolo.

Traduzione dal croato: Rosalba Molesi

\footnotetext{
${ }^{31}$ Si tratta in primo luogo del complesso di dodici sculture lignee raffiguranti gli apostoli che il vescovo acquistò a Venezia. Le opere si presentavano però già vecchie e danneggiate. Il presule comunque si vantava del fatto di averle acquisite per soli dodici ducati, ossia un solo ducato ciascuna. Il reale valore artistico di queste opere è molto più alto, in quanto si tratta di sculture veramente pregevoli che possono essere attribuite a Francesco Terilli e quindi vanno datate al 1600 circa. In seguito le sculture subirono forti ridipinture e oggi si presentano in uno stato di conservazione pessimo, pertanto la quantificazione del contributo della bottega sarà possibile solo dopo il restauro che è estremamente necessario. N. KUDIŠ, D. TULIĆ, Novosti o korčulanskoj sakralnoj baštini 17. i 18. stoljeća, in Godišnjak grada Korčule, 12, Korčula, 2007, p. 114-117. Il presule acquistò nel 1801 anche un'altra scultura lignea raffigurante la Pietà, che ora si trova nella chiesa di Ognissanti sempre nella città di Curzola. Anche in questo caso, è stato appurato che si tratta di un capolavoro della scultura lignea veneziana di Antonio Corradini realizzata nel secondo decennio del Settecento. D. TUliĆ, Una Pietà lignea di Antonio Corradini a Curzola (Korčula), in Arte Documento, 23, Venezia, 2007, p. 188-195.

${ }^{32}$ S. PIPLOVIĆ, Radovi u Korčulanskoj katedrali između svjetskih ratova, in 700 godina korčulanske biskupije, I. FISKOVIĆ, M. STANIĆ (a cura di), Korčula 2005, p. 272-281.
} 


\section{PREUREĐENJE UNUTRAŠNJOSTI KORČULANSKE KATEDRALE U 18. STOLEĆU}

U 17 i 18. stoljeću obnavljaju se i preuređuju sve korčulanske crkve, a među njima i katedrala svetog Marka. Iako građena u 15. stoljeću, ova se trobrodna i troapsidalna bazilika, s galerijama te drvenim poluvaljkastim svodom u glavnom brodu, doimlje stilski starijom, kao da je riječ o romaničkom zdanju. U 17. su stoljeću, točnije 1626., a po nalogu biskupa Jakova Fagagne probijeni bočni prozori na sve tri apside katedrale kako bi se dobilo više svijetla u prezbiteriju. U 18. će stoljeću intervencije u stari prostor katedrale biti obuhvatnije i složenije ponajprije u njezinom svetištu. Godine 1750. pod ciborij Marka Andrijića iz 1486. postavljen je novi mramorni oltar kako bi se u njega smjestio kovčeg s relikvijama svetog Todora, donesenih iz Rima 1736. godine. Mramorni je stipes djelo dosad slabo poznatog venecijanskog kipara Bortola Modola (Venecija, 1684. - 1771.) dok je klesarske radove izveo njegov uobičajeni poslovni suradnik, altarist Iseppo Caribolo. Ovaj je reljefni stipes najranija mramorna figuralna kompozicija u gradu Korčuli.

Najobimniji zahvat u katedrali učinjen je prema odredbama posljednjeg korčulanskog biskupa Josipa Kosirića (1787. - 1802.). O njegovim je zahvatima dosada pisano, no pretežno s negativnim stajalištem te bez pomnije analize istih. Biskupov radikalni zahvat, odnosno micanje starog i unošenje novog inventara u crkvu, slijedilo je tadašnje uobičajene primjere kasnobaroknih restauracija, primjerice one u katedralama Novigrada, Poreča, Osora, Raba i Zadra. Iz njegovih se intervencija može iščitati želja za uspostavljanjem što potpunije simetrije unutar prostora, za dobivanjem više svjetla u tamnom interijeru te za uvođenjem modernijeg liturgijskog namještaja. Tako je biskup naložio da se sruši velika kamena propovjedaonica na osam stupova iz 1445., a koja je remetila njegovu težnju za simetrijom - važnim principom regulacije interijera u odmaklom 18. stoljeću. To se može zaključiti iz činjenice da je maknuvši staru, dao sagraditi dvije manje propovjedaonice od drva, postavljajući ih simetrično jednu nasuprot druge. Biskup je raščistio prezbiterij uklanjajući oltar Uzašašća s malenim ciborijem, stare korske klupe te gredu s raspelom nad ulaskom u kor. Snizio je ciborij nad glavnim oltarom te na njega postavio drveni kip uskrslog Krista, slično kako je to 1782. učinjeno na ciboriju zadarske katedrale. Nabavio je u Veneciji novi mramorni tabernakul 1791., da bi istog zamijenio većim 1796. godine. Obijelio je sve kamene zidove i arhitektonsku plastiku u unutrašnjosti, proširio uske gotičke prozore glavnog broda te postavio novi ravni strop prekriven štukom, a po uzoru na raskošnije istovremene nove svodove u katedralama Raba i Zadra. Istovremeno je nabavio i drvene kipove apostola te ih smjestio otvore galerija u glavnom brodu.

Međutim, čini se da su sve nabrojene intervencije bile tek posljedica nemogućnosti provođenja u djelo jedne zamisli koju valja ovdje detaljnije i preciznije interpretirati. Riječ je o planiranom, no nikad izvedenom zahvatu, dokumentiranom na prikazu tlocrta svetišta korčulanske katedrale, a što se čuva u Državnom arhivu u Dubrovniku. Ovaj je projekt slabo poznat te zahtjeva novo iščitavanje. Biskup je planirao radikalnu modernizaciju svetišta, a ona je podrazumijevala rušenje Andrijićevog ciborija te postavljanje novog mramornog oltara u središte prezbiterija. Oltar je, po uzoru na tipologiju venecijanskih setečentističkih oltara Giorgia Massarija, trebao imati tabernakul u sredini, a sa strana dva kipa, najvjerojatnije anđela adoranata ili svetih zaštitnika grada, Marka Evanđelista i Todora Mučenika. U apsidu bez ciborija namjeravao je napraviti novi polukružni kor za kanonike zajedno s dodanim sjedalima za obične svećenike te biskupskom katedrom u središtu. Veliki podij s tronom i baldahinom planirao je postaviti s lijeve strane svetišta među stupove glavne lađe.

Ovakva modernizacija svetišta nije bila neobičan niti izoliran primjer. Dovoljno se sjetiti da su benediktinske redovnice svete Marije u Zadru, porušile ciborij kralja Kolomana na glavnom oltaru da bi na njegovu mjestu, između 1759. i 1762. mletački altarist Lorenzo Bon sagradio oltar s velikim tabernakulom kojeg flankiraju dva anđela Giovannija Marije Morlaitera. Istog je oblika bilo i nešto ranije te svakako manje radikalno rješenje za glavni oltar trogirske katedrale. Pod njezin je ciborij 1738. biskup Giuseppe Caccia ugurao mramorni oltar s tabernakulom kojeg flankiraju kipovi trogirskih zaštitnika, svetog Lovre i svetog Ivana Orsinija, djela venecijanskog kipara Giuseppea Torrettija. Do 
tlocrtom planiranog preuređenja svetišta korčulanske katedrale nasreću nije došlo, najvjerojatnije zbog velikih troškova, posebice nabave mramornog oltara s kipovima iz Venecije te protivljenja kanonika. Može se zaključiti kako je uklanjanje starijeg namještaja imalo za cilj postizanje simetrije, a bijeljenje zidova te širenje prozora, težnju za dobivanje jačeg osvjetljenja - glavnog sredstva u postizanju liturgijski što sugestivnijeg ambijenta. Neizvedeni plan uklanjanja ciborija te gradnje izoliranog tabernakulskog oltara s polukružnim korom iza njega, svjedoči o pokušaju da se u prostor drevne dalmatinske katedrale unesu moderne promjene, tipične za drugu polovicu 18. stoljeća.

Ključne riječi: Korčulanska katedrala, biskup Jsip Kosirić, barokizacija, Bortolo Modolo, projekt obnove svetišta, 18. stoljeće 